\title{
Levantamento de plantas de baixa inflamabilidade em áreas queimadas de Cerrado no Distrito Federal e análise das suas propriedades físicas
}

\author{
Survey of low flammability plants in burned areas of Cerrado in the Federal District and \\ analysis of their physical properties
}

Michel Aquino de Souza ${ }^{\mathrm{I}}$, Ailton Teixeira do Vale ${ }^{\mathrm{II}}$

\begin{abstract}
Resumo
Os incêndios florestais se propagam principalmente através do material combustível superficial. Portanto, plantas de baixa inflamabilidade podem ser usadas para proteção contra incêndios, pois dificultam a propagação do fogo. Neste sentido, o objetivo deste trabalho foi realizar um levantamento de plantas de baixa inflamabilidade no cerrado do Distrito Federal e, a partir de amostras coletadas, caracterizá-las. O levantamento dessas plantas deu-se por meio do caminhamento em áreas queimadas, fotografando espécimes relativamente preservados adjacentes à vegetação consumida pelas chamas. Depois, coletaram-se amostras de folhas das espécies de baixa e de alta inflamabilidade para caracterização das propriedades físicas, foliares e análise imediata. As espécies classificadas como de baixa inflamabilidade foram: Vochysia thyrsoidea, Palicourea rigida e Lavoisiera bergii. Já a gramínea Echinolaena inflexa foi considerada de alta inflamabilidade. As análises mostraram que, em comparação com Echinolaena inflexa, as espécies Vochysia thyrsoidea, Palicourea rigida e Lavoisiera bergii apresentaram bons índices que as habilitam como espécies de baixa inflamabilidade. Entre elas, Palicourea rigida destaca-se ao apresentar elevado teor de umidade $(173 \%)$, maior espessura foliar $(5,6 \mathrm{~mm})$, teor de voláteis de $76 \%$ e calor de combustão na umidade de campo de $1.263 \mathrm{cal} / \mathrm{g}$. Os resultados confirmaram a baixa inflamabilidade de Vochysia thyrsoidea, Palicourea rigida, e Lavoisiera bergii sendo estas indicadas para uso em aceiros verdes.
\end{abstract}

Palavras-chaves: Aceiro verde; Palicourea; Vochysia; Incêndios florestais

\begin{abstract}
The forest fires spread mainly through the surface of combustible material. Therefore, low flammability plants can be used for the protection against forest fires because these plants hinder the spread of fire. In this regard, the objective was to make a poll to find low flammability plants occurred in cerrado (savanna) of Distrito Federal in burned areas, and, after collecting samples, catalog their characteristics. It was done by plotting and photographing specimens of preserved adjacent vegetation consumed by the flames. Then, samples of high and low flammability leaves were collected to number their particular physical and foliar properties and make an immediate analysis. The samples classified as low flammability plants were: Vochysia thyrsoidea, Palicourea rigida, Lavoisiera bergii. The sample of the grass Echinolaena inflexa, was considered of high flammability. Comparing the Echinolaena inflexa Vochysia thyrsoidea, Palicourea rigida and Lavoisiera bergii, they presented good indexes that enable them to be of low flammability species, especially the Palicourea rigida which presented high moisture content $(173 \%)$, higher foliar thickness $(5.6 \mathrm{~mm})$, volatile contents of $76 \%$ and combustion heat in the field moisture of $1263 \mathrm{cal} / \mathrm{g}$. The results confirmed the low flammability of Vochysia thyrsoidea, Palicourea rigida and Lavoisiera bergii being these indicated for the use in green firebreaks.
\end{abstract}

Keywords: Green firebreak; Palicourea; Vochysia; Forest fires

\footnotetext{
I Biólogo, MSc., Bombeiro Militar Professor do Colégio Militar Dom Pedro II, SAIS AE 03, Qd. 4 Lt. 05, CEP 70.602-900, Brasília (DF), Brasil. michel.souza@cbm.df.gov.br (ORCID: 0000-0002-6413-4134)

II Engenheiro Florestal, Dr., Professor Associado da Universidade de Brasília, Campus Universitário Darcy Ribeiro, Asa Norte, CEP 70910-900, Brasília (DF), Brasil. ailton.vale@gmail.com (ORCID: 0000-0001-5579-2381)
} 


\section{Introdução}

O cerrado passa sazonalmente por uma estação seca na qual praticamente não chove. Isso, associado às altas temperaturas do ar e ventos fortes, potencializa as condições favoráveis para a ocorrência e propagação de incêndios florestais levando o fogo a consumir áreas cada vez maiores. Propriedades da vegetação podem contribuir para uma maior ou menor velocidade de propagação dos incêndios. $O$ tipo de combustível é o principal potencializador ou retardador da propagação, visto que as outras variáveis são praticamente incontroláveis (clima, tempo e relevo). As técnicas contra propagação do fogo dentro da silvicultura preventiva objetivam interferir na continuidade, quantidade e na qualidade dos combustíveis florestais.

Uma estratégia protetiva é a substituição da vegetação suscetível por espécies que possam inibir a propagação do fogo. Plantas de baixa inflamabilidade são usadas como mais uma ferramenta de gestão dos incêndios florestais. A gestão da paisagem sob risco de fogo pode incluir tais espécies em aceiros verdes. Elas devem ser implantadas perpendicularmente à direção dos ventos da seca, adjacentes a estradas e aceiros, servindo ainda como quebra-vento e cerca viva, constituindo-se como barreiras verdes. Portanto, características foliares, como o teor de umidade, a constituição química e energética, a disposição e espessura, interferem diretamente na propagação do fogo na vegetação.

O teor de umidade é determinante da inflamabilidade dos combustíveis vegetais. A umidade foliar em geral vai de $300 \%$, na folhação, a $50 \%$, na senescência. Somente incêndios de média a alta intensidade podem consumir as plantas vivas até $7 \mathrm{~cm}$ de diâmetro que geralmente apresentam umidade de 75 a $150 \%$ de sua massa seca (SOARES; BATISTA, 2007). Dessa forma, a umidade do tecido, os óleos essenciais voláteis e a superfície vegetal condicionam a inflamabilidade. $\mathrm{O}$ teor de umidade aumenta a capacidade térmica do tecido e inibe o ardor da combustão. O conteúdo mineral e o teor de voláteis influenciam diretamente a inflamabilidade (WHITE; ZIPPERER, 2010).

A quantidade de água que passa pela folha é diretamente proporcional à espessura foliar em função da nervação (TIAN; SHU; WANG, 2007). A espessura foliar interfere diretamente no tempo para liberação do vapor de água e dos gases combustíveis que têm uma distância a percorrer do mesófilo para superfície. O fluxo de gases da pirólise é iniciado pela decomposição da hemicelulose, seguido da celulose e depois da lignina que, em contato com o oxigênio do ar, formam as chamas (RODRÍGUEZ, 2010). Hull et al. (2012) explicaram que folhas finas secam rapidamente e logo se inflamam, enquanto folhas grossas acumulam mais água e demoram mais para aquecer e se inflamar obedecendo uma sequência.

Desse modo, o pré-aquecimento, a combustão dos gases e a incandescência (combustão do carbono fixo) constituem as três fases que se sobrepõem no desenvolvimento do incêndio florestal. No préaquecimento, ocorre a secagem pela eliminação de vapor de água. Depois, de 260 a $400^{\circ} \mathrm{C}$ (temperatura de inflamação), se inicia a pirólise dos combustíveis próximos às chamas. $\mathrm{O}$ tempo transcorrido para isso dependerá das espécies envolvidas e suas características de umidade, constituição, maturação e espessura (RODRÍGUEZ, 2010) levando a uma maior ou menor liberação de calor.

O calor de combustão é a efetiva liberação de calor em razão da queima total de uma unidade de massa. O comportamento das chamas no incêndio está relacionado com a umidade do combustível. Ela determina a disponibilidade do combustível para queima e seu consumo, pois gasta-se calor para a retirada da umidade durante a combustão (MARTIN et al., 1993). Soares e Batista (2007) referenciaram o poder calorífico das folhas de espécies florestais até $8.400 \mathrm{cal} / \mathrm{g}$ em acículas. As resinas e óleos vegetais, por terem um maior conteúdo energético que a celulose, definem um maior calor de combustão e antecipam a inflamabilidade.

Naturalmente, a inflamabilidade da vegetação considera quatro fatores: a inflamabilidade que é o tempo para a ignição; a sustentabilidade que é a manutenção da queima mesmo retirada a fonte de calor; a combustibilidade que é velocidade de queima; e a consumabilidade que é a quantidade consumida pelo fogo. (ANDERSON, 1970; MARTIN et al., 1993). O aquecimento inicia a secagem com liberação de vapor de água. Depois, ocorre a vaporização dos óleos essenciais, das resinas e hidrocarbonetos constituindo os gases de pirólise. Portanto, a facilidade de ignição e propagação do fogo é determinada pela inflamabilidade. Consequentemente, as chamas são causadas pela transferência de calor que é diretamente 
proporcional ao poder calorífico do combustível em função de sua composição (RODRÍGUEZ, 2010). Isso leva o início da combustão ao ponto de inflamação, que varia de 220 a $298^{\circ} \mathrm{C}$ (CIANCIULLI, 1981; HEIKKILÄ; GRÖNOVIST; JURVÉLIUS, 1993).

Além do ponto de inflamação alto, as plantas de baixa inflamabilidade são resistentes à seca e sem desfolha no inverno, apresentam alta nervação das folhas (indicando abundante transporte de água) e alto teor de umidade, não são resinosas, nem oleosas ou cerosas. Ainda apresentam menor acúmulo de detritos e galhos mortos, têm padrão de ramificação solto. As características que afetam sua inflamabilidade são a composição química (lignina, água, sais minerais e voláteis), a proporção entre área e volume da copa, a densidade, a arquitetura da planta, a quantidade de material morto e vivo nas copas e o material morto na planta e no solo. (BATISTA; BIONDI, 2009).

Por outro lado, espécies vegetais caracterizadas como de alta inflamabilidade apresentam óleos essenciais, alto teor de materiais voláteis e folhas secas presas aos ramos (WHITE; ZIPPERER, 2010). As gramíneas são classicamente referenciadas como tendo uma alta inflamabilidade. Sua fenologia expressa sazonalmente uma dormência no período de estiagem com secagem das folhas e de toda parte aérea. Isso contribui para um aumento significativo de sua inflamabilidade. No entanto, perdem em torno de $90 \%$ da fitomassa aérea pela queimada (ONIGEMO, 2007).

De modo geral, aceiro (ou barreira) verde é uma técnica de prevenção para impedir ou reduzir a velocidade e a intensidade das chamas, evitando que alcance as copas. Ela consiste no "plantio de uma faixa de vegetação com espécies de baixa inflamabilidade, que ofereçam resistência à propagação do fogo", principalmente pelo conteúdo de umidade. O objetivo é mudar o comportamento do fogo na transição com a vegetação a proteger, servindo como suporte para ações de combate e queima controlada (BATISTA; BIONDI, 2009). As plantas de baixa inflamabilidade se configuram como mais uma estratégia na proteção contra incêndios florestais em aceiros verdes.

Desse modo, os aceiros verdes devem ser estrategicamente implantados considerando a topografia, a insolação, o solo, a direção do vento predominante, entre outros parâmetros, especialmente a inflamabilidade das espécies que o comporão (BATISTA et al., 2012). Comparado com aceiros negros e tradicionais, eles podem reduzir a erosão e as doenças, com vantagens econômicas e ecológicas. Tian, Shu e Wang (2007) informam que aceiros verdes têm sido feitos com a plantação de árvores como Schima superba sobre aceiros tradicionais no sul da China. Eles testaram a eficácia do aceiro verde como barreira à propagação de um incêndio que atingiu as copas de $8,5 \mathrm{~m}$ de altura com intensidade de até $28.379 \mathrm{~kW} / \mathrm{r}$. Isso levou a queima apenas da primeira fila das 6 filas de Schima superba com 13 anos de idade.

Portanto, associadas aos aceiros tradicionais, as plantas de baixa inflamabilidade podem ser utilizadas na proteção aos incêndios florestais em áreas de restauração, em casas na interface urbano florestal e em unidades de conservação. Em áreas de cerrado, a estratégia é implantar aceiros verdes, evitando a dominância de gramíneas, criando um mosaico de inflamabilidade, com plantas de baixa inflamabilidade, integrando a silvicultura preventiva.

Diante do exposto, objetivou-se realizar um levantamento de plantas de baixa inflamabilidade em áreas queimadas por incêndios florestais do cerrado e a caracterização física das folhas das espécies selecionadas em comparação a uma espécie de alta inflamabilidade, com vistas à indicação de plantas de baixa inflamabilidade para aceiros verdes.

\section{Material e métodos}

\section{Levantamento de campo}

O trabalho foi realizado no Distrito Federal, onde o clima predominante é o Tropical Sazonal, de inverno seco, com temperatura média anual de $22,5^{\circ} \mathrm{C}$ e precipitação média anual de $1200 \mathrm{a} 1800 \mathrm{~mm}$. $\mathrm{O}$ levantamento de plantas de baixa inflamabilidade em áreas incendiadas foi feito pela constatação visual de menor queima do espécime em comparação com a vegetação adjacente. Essas áreas foram identificadas pela visualização direta do incêndio ativo e de áreas incendiadas, além de informações de bombeiros militares. Entre agosto e setembro de 2013, foram localizadas e visitadas sete áreas de incêndios, totalizando 
aproximadamente 40 ha de áreas incendiadas em fitofisionomias de cerrado sensu stricto, cerradão, mata de galeria, vereda, campo sujo, campo limpo, cerrado rupestre.

Nas áreas incendiadas analisadas, predominou a fitofisionomia de cerrado sensu stricto e cerradão. Para o levantamento das espécies de baixa inflamabilidade, fez-se o caminhamento pela área queimada, até quatro dias após o incêndio florestal. Fotografava-se o espécime de folhas vivas relativamente preservadas ao lado da vegetação altamente consumida pelas chamas. As coordenadas geográficas foram registradas,

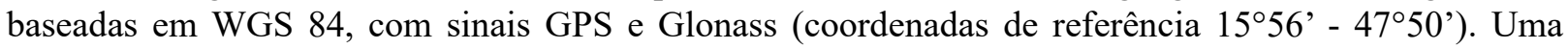
análise visual preliminar foi feita para escolha daquelas espécies que apresentavam características de baixa inflamabilidade. O critério de escolha dessas espécies foi a visualização de plantas que não tiveram suas folhas consumidas pelo fogo. Foram observados vários indivíduos das espécies de interesse com folhas apresentando-se relativamente mais preservadas das chamas que a vegetação adjacente. As espécies foram selecionadas para posteriormente serem coletadas suas amostras foliares.

\section{Coleta de amostras foliares}

A coleta de folhas maduras foi realizada nos dias 21, 22 e 23 de setembro de 2013 e nos dias 1 e 2 de setembro de 2014, no auge da seca. Nesses dias, a temperatura máxima variou entre 31,4 a $34,6^{\circ} \mathrm{C}$, a umidade relativa do ar média entre $43 \%$ e $57 \%$, e a velocidade do vento durante o dia ficou entre 0,3 e 2,3 $\mathrm{m} / \mathrm{s}$. Esses dados foram obtidos da estação meteorológica Roncador - DF (coordenadas $-15^{\circ} 55^{\prime}$ - $47^{\circ} 52^{\prime}$ ) localizada na área do IBGE (Instituto Brasileiro de Geografia e Estatística) próximo à FAL (Fazenda Água Limpa).

Aleatoriamente foram escolhidos três locais distintos na FAL nos quais foram coletadas amostras de folhas verdes (não secas) incluindo o pecíolo de Vochysia thyrsoidea, Palicourea rigida e Lavoisiera bergii, perfazendo de 6 a 12 amostras para cada espécie selecionada no levantamento de campo. Sendo as gramíneas consideradas de alta inflamabilidade, para fins de comparação, coletaram-se também amostras de Echinolaena inflexa (Poir.) Chase (Poaceae). Exsicatas e duplicatas foram depositadas no herbário da Universidade de Brasília sob os números 11, 12, 13 e 14 Souza, M. A. 2 IX 2014, respectivamente.

Os indivíduos foram fotografados e tiveram suas coordenadas de localização registradas (referência $\left.-15^{\circ} 57^{\prime}-47^{\circ} 54^{\prime}\right)$. As folhas foram acondicionadas em sacos de polietileno vedados e guardadas ao abrigo do sol e, posteriormente, em geladeira (cerca de $8^{\circ} \mathrm{C}$ ) para diminuir a evapotranspiração foliar. Essas folhas foram utilizadas nas análises laboratoriais.

\section{Análises de laboratório}

A desidratação das folhas para determinação do teor de umidade baseou-se na norma ABNT NBR 7190 (1997). A água da evapotranspiração, que ficou confinada nas embalagens durante o transporte do campo para o laboratório, foi proporcionalmente somada à massa fresca das folhas, encontrando-se a massa úmida. Em seguida, as amostras foram colocadas em estufa a $\pm 9^{\circ} \mathrm{C}$ (ZHANG; ZHANG; ZHOU, 2011; BATISTA et al., 2012; DIMITRAKOPOULOS; MITSOPOULOS; KALIVA, 2013). Na sequência, foi realizada, de forma sucessiva e periódica, a determinação da massa até que ela se tornasse constante, utilizando balança com sensibilidade de $10^{-4} \mathrm{~g}$.

A medição da espessura das folhas foi realizada com paquímetro digital com sensibilidade de $10^{-2}$ $\mathrm{mm}$, em pelo menos 6 folhas de cada espécie. Para a medida da área foliar, a folha foi prensada sobre um papel centimetrado e seu contorno desenhado. Em função da variação de forma e tamanho das folhas, foram utilizados dois métodos para estimar o volume foliar, o método da balança hidrostática, segundo Vital (1984), e pelo produto entre área e espessura.

As amostras secas foram moídas em moinho de facas e, em seguida, classificadas em três classes granulométricas (cg): $\mathrm{cg} \geq 0,425 \mathrm{~mm} ; 0,425 \mathrm{~mm}<\mathrm{cg}<0,25 \mathrm{~mm}$ e $\mathrm{cg} \leq 0,25 \mathrm{~mm}$. A análise imediata baseou-se na norma ABNT NBR 8112 (1986), porém, elas foram analisadas em triplicata.

A determinação do poder calorífico superior baseou-se na norma ABNT NBR 8633 (1984), com adaptações do Laboratório de Produtos Florestais/Setor Energia de Biomassa, utilizando-se calorímetro 
da marca Parr. O calor de combustão das folhas na condição de campo, ou seja, úmida, foi determinado pela equação de Soares e Batista (2007): $H w=H d\{[100-(U / 7)] /(100+U)\}$, em que: $H w=$ poder calorífico úmido $(\mathrm{kcal} / \mathrm{kg}) ; H d=$ poder calorífico superior do material seco $(\mathrm{kcal} / \mathrm{kg})$; e $U=$ teor de umidade do material (\%) (base seca).

Os dados de todos os ensaios foram analisados estatisticamente por meio de Análise de Variância (ANOVA) em Delineamento Inteiramente Casualizado (DIC) para as variáveis estudadas, considerando as espécies selecionadas. Quando foi o caso, utilizou-se o teste "t" para comparação das médias. Para análise dos dados foi utilizado o programa ASSISTAT Versão 7.7 beta (SILVA; AZEVEDO, 2009).

Finalmente, para inter-relacionar todos os dados, foi feito um ranqueamento das espécies estudadas, quanto às características de inflamabilidade a partir do produto entre a nota (de 1 , menor inflamabilidade relativa na variável, a 4, maior inflamabilidade) e um peso (de 1 a 5 quanto maior for a relação da variável com a baixa inflamabilidade). O peso 5 foi atribuído ao calor de combustão na umidade de campo, pois ele revela a quantidade de calor liberado para propagação do incêndio nas folhas na umidade em que se encontram no auge da seca, refletindo a combustibilidade e a energia para propagação das chamas. $\mathrm{O}$ peso 4 foi conferido ao teor de umidade, devido a sua forte influência para inflamabilidade, pois a chama só é possível após o avanço da frente de secagem que se relaciona diretamente com o tempo para o aparecimento da chama. Os gases de pirólise são provenientes dos materiais voláteis existentes nas folhas, por isso foi conferido o peso 3 ao teor de voláteis. A ação do calor sobre o tecido foliar ocorre em camadas de forma que primeiro tem-se a frente de secagem, seguida pela frente de pirólise. Portanto, a espessura relaciona-se com o tempo e a distância para avanço dessas frentes e, por isso, recebeu o peso 2. Por fim, o poder calorífico superior representa todo o calor que a biomassa foliar pode fornecer para propagação do incêndio durante todo o processo de queima e, por isso, recebeu o menor peso, mas é importante para determinação do calor de combustão na umidade de campo.

\section{Resultados e discussão}

\section{Levantamento de plantas de baixa inflamabilidade em áreas queimadas}

O levantamento de campo resultou na classificação de três plantas. Nas Figuras 1, 2 e 3 são apresentadas fotografias representativas das plantas classificadas como de baixa inflamabilidade pelo levantamento. Foram fotografados 48 indivíduos de Vochysia thyrsoidea Pohl (Vochysiaceae), 34 de Palicourea rigida H.B.K. (Rubiaceae), e 6 agrupamentos de Lavoisiera bergii Cogn. (Melastomataceae).

Vochysia thyrsoidea tem hábito arbóreo sempre verde podendo chegar a $18 \mathrm{~m}$ de altura no cerrado, possui ramos espessos e copa umbeliforme, sementes aladas disponíveis de outubro a novembro e ocorre em cerrado stricto senso e cerradão (HARIDASAN, 2006; SILVA JÚNIOR; SANTOS, 2005). Palicourea rigida tem hábito arbustivo a arbóreo, contendo grande nervação, característica que contribui para sua baixa inflamabilidade e apresenta-se sempre verde com queda foliar concentrada no mês de setembro (PIRANI; SANCHEZ; PEDRONI, 2009). Essa fenologia favorece a baixa inflamabilidade de ambas, pois começam a perder as folhas no início das chuvas, enquanto recompõem as folhas jovens. Sendo nativas do cerrado, estas espécies apresentam boa adaptação e resistência ao período de seca e ainda têm padrão de ramificação solto e não retêm folhas e galhos mortos.

Lavoisiera bergii tem hábito subarbustivo de até $1,3 \mathrm{~m}$ de altura e pequenas folhas inseridas quase verticalmente em um caule de 1,9 mm de diâmetro em média (MUNHOZ; EUGÊNIO; OLIVEIRA, 2011). Já Echinolaena inflexa é uma erva perene com até $0,6 \mathrm{~m}$ de altura que apresenta dormência no período da seca, mantém as folhas senescentes propiciando a propagação de incêndios. Ela ocorre com alta frequência em campos, cerrado sensu stricto e áreas úmidas (ALMEIDA et al., 1998; MUNHOZ; EUGÊNIO; OLIVEIRA, 2011). 
Figura 1 - Vochysia thyrsoidea (altura $\pm 1,3 \mathrm{~m}$ ) preservada em relação à vegetação adjacente consumida pelas chamas.

Figure 1 - Vochysia thyrsoidea (height $\pm 1.3 \mathrm{~m}$ ) preserved in relation to adjacent vegetation consumed by fire.

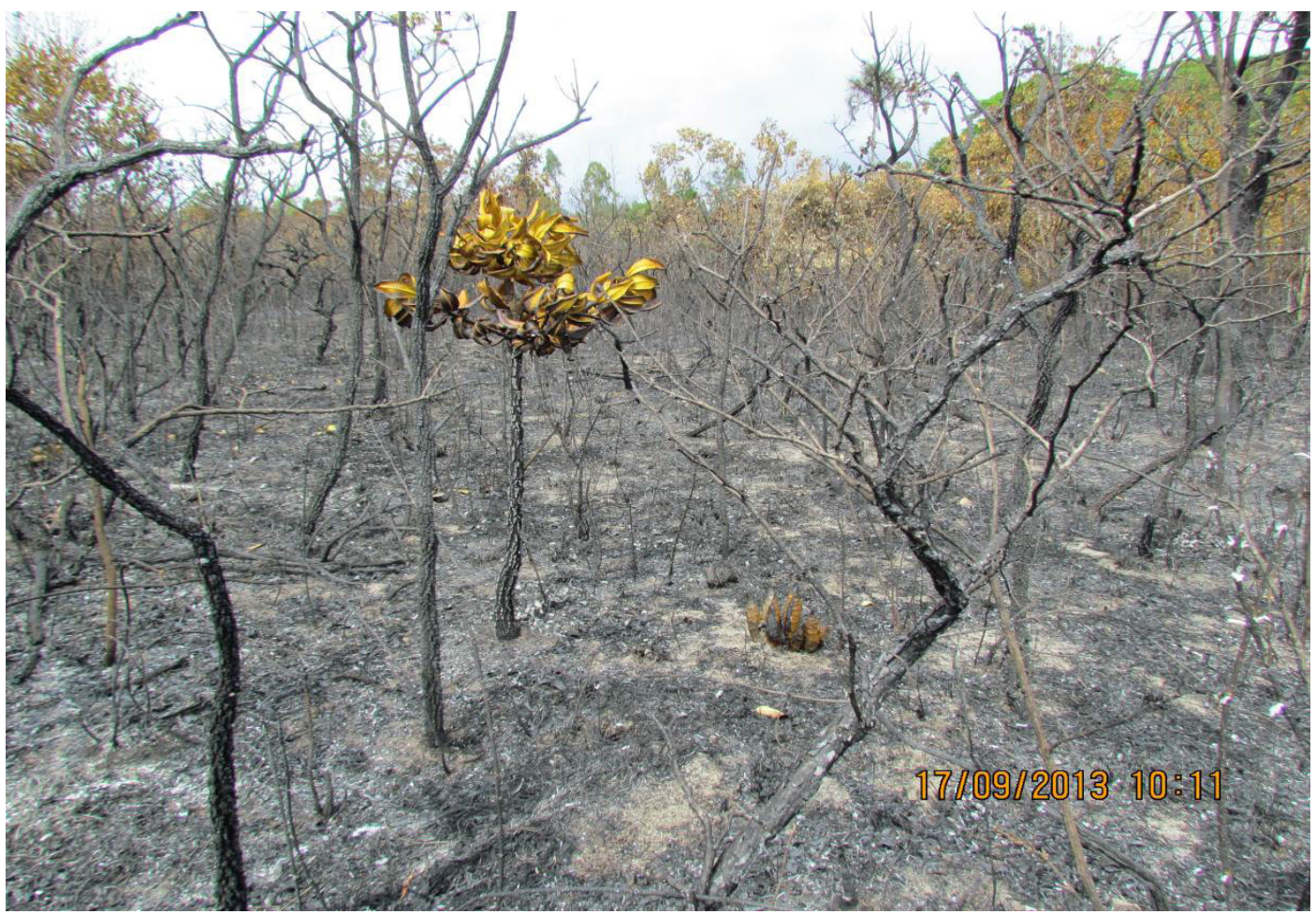

Figura 2 - Palicourea rigida $( \pm 90 \mathrm{~cm})$ relativamente preservada em comparação com a vegetação adjacente.

Figure 2 - Palicourea rigida $( \pm 90 \mathrm{~cm})$ relatively preserved in comparison with the adjacent vegetation.

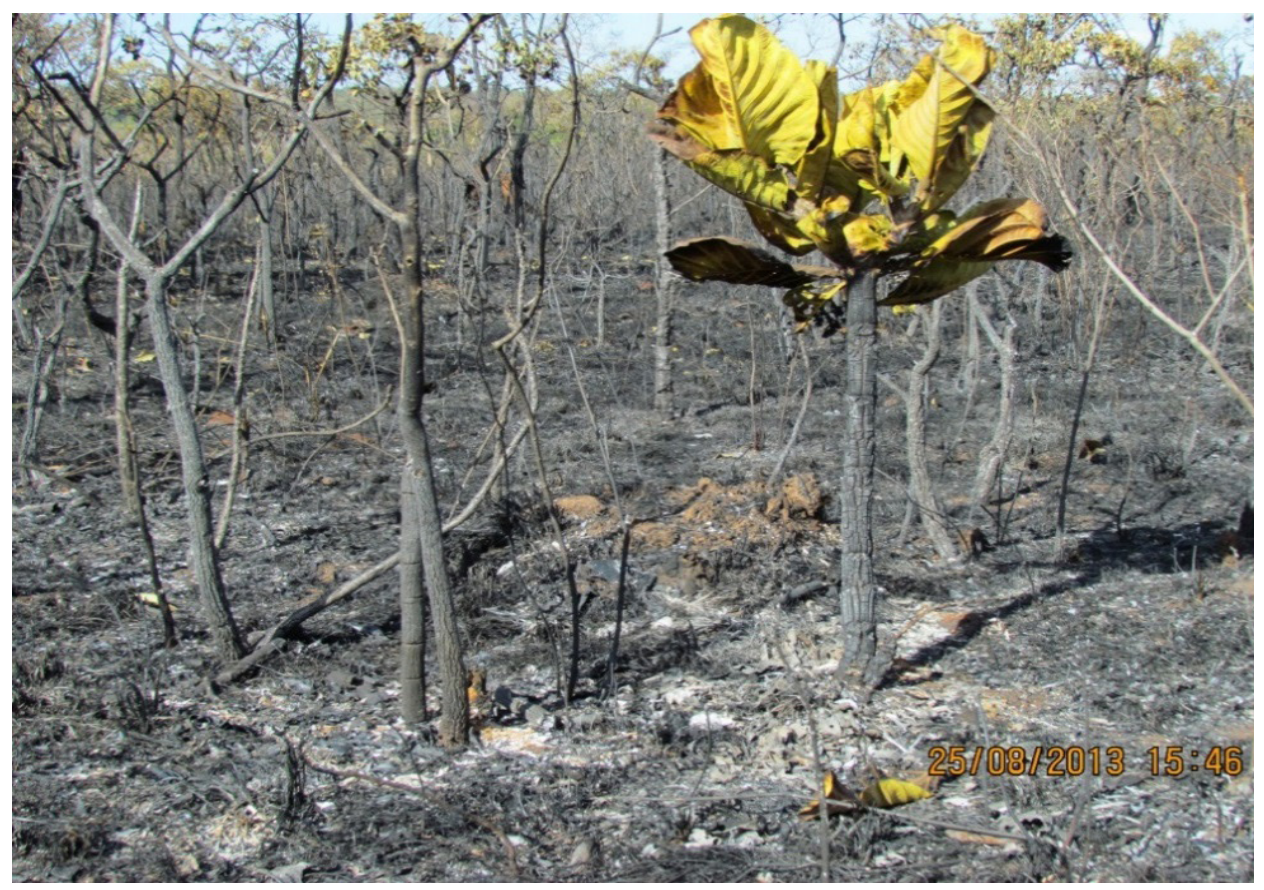


Figura 3 - Lavoisiera bergii $( \pm 50 \mathrm{~cm})$ relativamente preservada do consumo das chamas, enquanto a vegetação adjacente foi completamente queimada.

Figure 3 -Lavoisiera bergii $( \pm 50 \mathrm{~cm})$ relatively preserved consumption flames while the adjacent vegetation was completely burned.

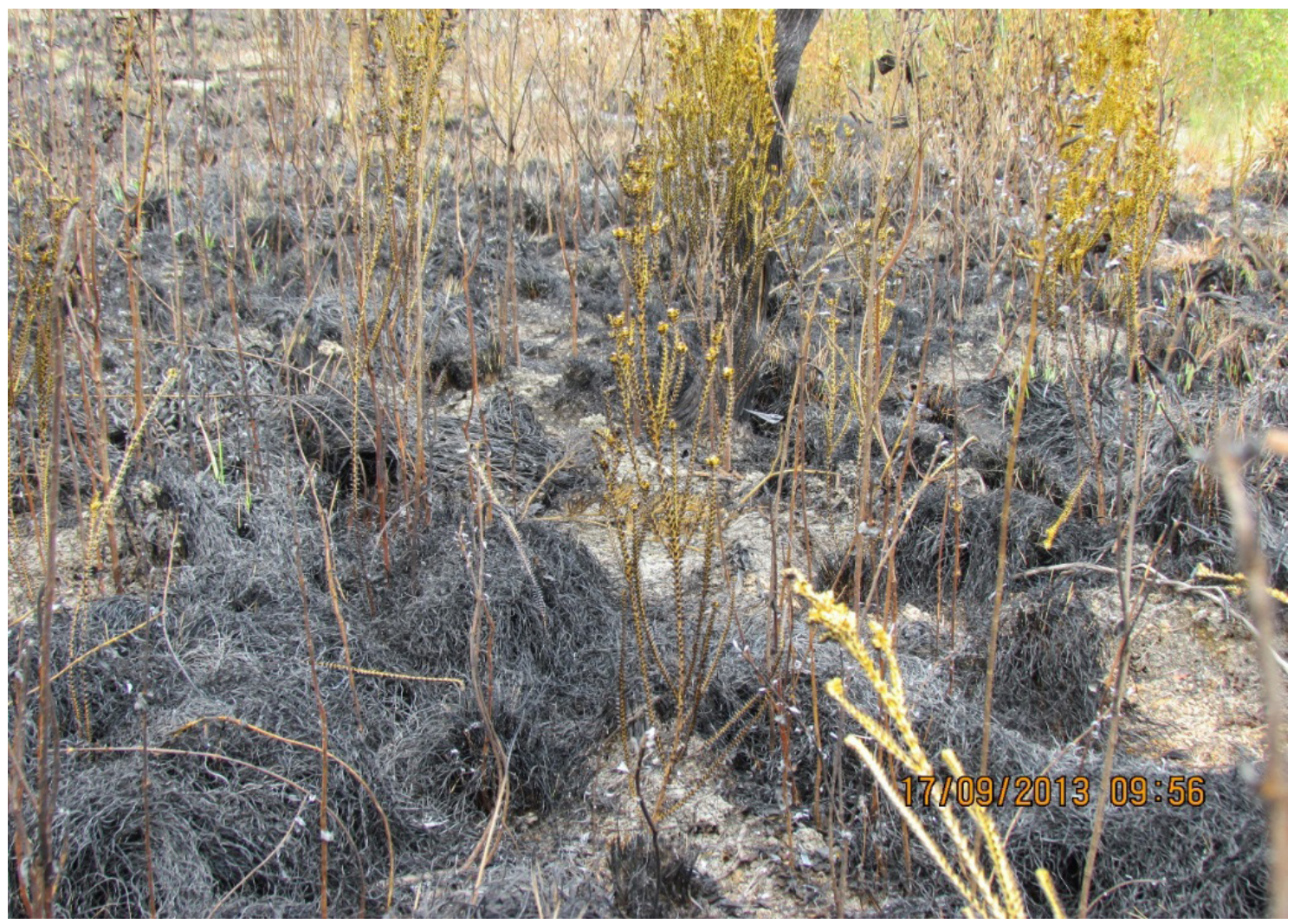

\section{Teor de umidade e dimensões foliares}

Entre as espécies estudadas, houve diferença significativa a 1\% de probabilidade para a variável teor de umidade e os resultados com o teste de média são apresentados na Tabela 1.

Tabela 1 - Resultado da análise de médias pelo teste " $t$ " dos teores de umidade em base seca e dimensões das folhas das espécies selecionadas.

Table 1 - Results of the analysis by means of " $t$ " test the moisture content on a dry basis and dimensions of the leaves of the selected species.

\begin{tabular}{|c|c|c|c|c|c|c|c|c|}
\hline Espécie & Umidade (\%) & & Área $\left(\mathrm{cm}^{2}\right)$ & & Espessura (cm) & & Volume $\left(\mathrm{cm}^{3}\right)$ & \\
\hline Lavoseiera bergii & 257,09 & $\mathrm{a}$ & 0,34 & $\mathrm{c}$ & 0,27 & $\mathrm{c}$ & 0,09 & $\mathrm{c}$ \\
\hline Palicourea rigida & 173,1 & $\mathrm{~b}$ & 630,05 & $\mathrm{a}$ & 0,56 & $\mathrm{a}$ & 21,67 & $\mathrm{a}$ \\
\hline Vochysia thyrsoidea & 145,62 & $\mathrm{c}$ & 182,77 & $\mathrm{~b}$ & 0,48 & $\mathrm{~b}$ & 5,63 & $\mathrm{~b}$ \\
\hline Echinolaena inflexa & 49,65 & d & $2,2 *$ & & 0,18 & $\mathrm{~d}$ & 0,41 & $\mathrm{c}$ \\
\hline
\end{tabular}

As médias seguidas pela mesma letra não diferem estatisticamente entre si. "Silva e Klink (2001). 
A espécie Lavoisiera bergii apresentou o maior teor de umidade que diferiu estatisticamente das demais. É uma espécie que ocorre preferencialmente em veredas e em locais com solo hidromórfico. Assim, seu alto teor de umidade está muito relacionado com a alta umidade do solo de ocorrência e não a mecanismos fisiológicos de xeromorfismo adaptativo. Vochysia thyrsoidea e Palicourea rigida apresentaram teores de umidades intermediários e estatisticamente diferentes entre si, mas ocorrem em cerrado com latossolo bem drenado. Seus elevados teores de umidade estão relacionados com mecanismos fisiológicos de adaptação à seca e às queimadas. Echinolaena inflexa apresentou o menor teor de umidade, como era de se esperar de uma gramínea, que no período de seca entra em um estado fisiológico de latência. Com isso, é natural que tenha um baixo teor de umidade, o que contribui sobremaneira para sua alta inflamabilidade.

O teor de umidade em base úmida $\left(\mathrm{U}_{\mathrm{bu}}\right)$ das quatro espécies foi: para Lavoisiera bergii, 71,26\%; Vochysia thyrsoidea 59,16\%; Palicourea rigida, 62,21\% e Echinolaena inflexa, 33,52\%. Murray, Hardstaff e Phillips (2013) encontraram plantas nativas da floresta esclerófila seca do sudeste australiano de baixa inflamabilidade com $\mathrm{U}_{\mathrm{bu}}$ variando de 40,12 a 77,23\%. A umidade de extinção em incêndio florestal é o conteúdo de umidade mínimo para que o combustível não entre em combustão e não se inflame, sendo de 25 a $35 \%$ de teor de umidade base seca $\left(\mathrm{U}_{\mathrm{bs}}\right)$. Dessa forma, supõe-se que para ocorrência da chama é necessário que as folhas atinjam esse patamar com secagem, pois o teor de umidade tem uma relação inversa com a inflamabilidade (RODRÍGUEZ, 2010; SOARES; BATISTA, 2007). A inflamabilidade da planta é mais influenciada pelo teor de umidade e quantidade de biomassa foliar (LONG et al., 2006).

Weise et al. (2005), estudando plantas ornamentais norte-americanas supostamente de baixa inflamabilidade, encontraram teores de umidade de 180 a 304\% $\left(\mathrm{U}_{\mathrm{bs}}\right)$. Batista e Biondi (2009) encontraram teor de umidade $\left(\mathrm{U}_{\mathrm{bs}}\right)$ de $169 \%$ para folhas de Ligustrum lucidum, considerando-a de baixa inflamabilidade e indicada para barreiras verdes no Brasil. No estudo de Tian, Shu e Wang (2007), Ligustrum lucidum apresentou o maior teor de umidade $(210,6 \%)$ e um alto tempo para ignição (62 s), mas apresentou uma alta taxa de liberação de calor. Batista et al. (2012) confirmaram a baixa inflamabilidade de Michelia champaca que apresentou teor de umidade base seca de 183,7\%. Schima superba, utilizada classicamente como aceiro verde na China, apresentou teor de umidade de $157 \%\left(\mathrm{U}_{\mathrm{bs}}\right)$ e 72 s para ignição. Michelia macclurei apresentou $143 \%$ de umidade e foi indicada para aceiro verde (TIAN; SHU; WANG, 2007; YONG-HUAN, 2007).

As grandes folhas de alta nervação e, consequentemente, alta hidratação de Palicourea rigida estão associadas à sua baixa inflamabilidade, pois proporciona-lhe maior área foliar, estatisticamente diferente das demais espécies. Ela apresenta nervuras espessas e salientes na face abaxial (SILVA JÚNIOR; SANTOS, 2005) que ultrapassam $8 \mathrm{~mm}$. Já as folhas diminutas de Lavoisiera bergii também apresentam baixa inflamabilidade, demonstrando que esse parâmetro por si não explica a baixa inflamabilidade. A disposição das folhas também favorece uma maior ou menor inflamabilidade, como é o caso de Vochysia thyrsoidea e Lavoisiera bergii que têm folhas dispostas quase verticalmente, diminuindo a área de contato com as chamas devido à inclinação. Silva e Klink (2001) encontraram área foliar de Echinolaena inflexa de $2,2 \mathrm{~cm}^{2}$, valor que foi utilizado na Tabela 1 . Apesar de Echinolaena inflexa ter folhas dispostas verticalmente, tem baixo teor de umidade.

As maiores nervação e hidratação foliares de Palicourea rigida favoreceram sua maior espessura e resistência às chamas. A maior espessura de Vochysia thyrsoidea pode compensar outras características não tão favoráveis à baixa inflamabilidade, como a área foliar. A espessura foliar do subarbusto Lavoisiera bergii (caule apresenta 1,9 mm de diâmetro em média) foi maior que de Echinolaena inflexa. Esta característica associada ao seu pequeno comprimento, forma de inserção no caule (cerca de $30^{\circ}$ ) e alta umidade, fazem com que Lavoisiera bergii mantenha sua umidade por mais tempo quando atingida pelas chamas. A menor espessura de Echinolaena inflexa (colmo tem em média $0,95 \mathrm{~mm}$ de diâmetro) está relacionada ao hábito herbáceo e é típico das gramíneas. As folhas diminutas de Lavoisiera bergii explicam o seu menor volume. Seus ramos (folhas e caule) apresentam cerca de $7 \mathrm{~mm}$ de espessura. $O$ fogo vai interagir não somente com as folhas, mas com os ramos, visto que se trata de um subarbusto. Dessa forma, considerando o volume do ramo, há uma diferença considerável entre Lavoisiera bergii e Echinolaena inflexa. O maior volume foliar de Palicourea rigida está relacionado com a quantidade de tecidos e enervações foliares.

Ci. Fl., Santa Maria, v. 29, n. 1, p. 181-192, jan./mar., 2019 
Murray, Hardstaff e Phillips (2013), estudando espécies da floresta esclerófila seca australiana, indicaram que folhas mais compridas ao serem aquecidas retêm mais calor e se inflamam mais rapidamente. Eles não encontraram diferenças significativas entre a espessura das folhas de espécies exóticas e nativas. Também não evidenciaram forte relação entre a espessura e a inflamabilidade, mas atribuindo menor inflamabilidade às nativas, explicaram que isso se deve à cutícula foliar espessa das espécies nativas como resposta xeromórfica. Tian, Shu e Wang (2007) relacionaram a anatomia foliar com a inflamabilidade, indicando que Camellia sinensis, por sua alta proporção de tecido paliçádico e esponjoso, tem favorecida a sua baixa inflamabilidade, como provavelmente ocorre com Palicourea rigida. Gauteame et al. (2013) encontraram a espessura de $0,032 \mathrm{~cm}$ em Pittosporum tobira de baixa inflamabilidade.

\section{Análise imediata e poder calorífico}

Pela análise de variância, observou-se diferença significativa entre as espécies para materiais voláteis, cinzas e carbono fixo superior ao nível de $1 \%$ de probabilidade. A ANOVA, para os dados de Poder Calorífico Superiores (PCS) das amostras coletadas, resultou em F não significativo, ao contrário do Poder Calorífico Úmido (PCU) que resultou em F significativo a 1\% de probabilidade. A Tabela 2 apresenta os resultados com o teste de média.

Tabela 2 - Médias dos teores de voláteis, cinzas e carbono fixo, Poder Calorífico Superior (PCS) e Calor de Combustão na Umidade de Campo (PCU) das espécies com resultados do teste de t.

Table 2 - Average of the levels of volatile, ash and fixed carbon, higher calorific value and combustion heat in the field moisture of the species with the $t$ test results.

\begin{tabular}{|c|c|c|c|c|c|c|c|c|c|}
\hline \multirow{3}{*}{$\frac{\text { Espécie }}{\text { Echinolaena inflexa }}$} & \multirow{2}{*}{\multicolumn{2}{|c|}{ Voláteis (\%) }} & \multirow{2}{*}{\multicolumn{2}{|c|}{ Cinzas (\%) }} & \multirow{2}{*}{\multicolumn{2}{|c|}{ Carbono (\%) }} & \multicolumn{3}{|c|}{ Poder calorífico (cal/g) } \\
\hline & & & & & & & \multirow{2}{*}{$\begin{array}{c}\text { Superior } \\
4.548\end{array}$} & \multicolumn{2}{|c|}{ Úmido } \\
\hline & 76,83 & a & 9,84 & $\mathrm{a}$ & 13,33 & $\mathrm{c}$ & & $2.869,40$ & $\mathrm{a}$ \\
\hline Palicourea rigida & 76,1 & $\mathrm{a}$ & 7,2 & $\mathrm{~b}$ & 16,7 & $\mathrm{~b}$ & 4.581 & $1.297,30$ & $\mathrm{c}$ \\
\hline Lavoseiera bergii & 73,9 & $\mathrm{~b}$ & 8,26 & $\mathrm{~b}$ & 17,84 & $\mathrm{ab}$ & 4.492 & 815,8 & $\mathrm{~d}$ \\
\hline Vochysia thyrsoidea & 73,58 & $\mathrm{~b}$ & 7,57 & $\mathrm{~b}$ & 18,85 & $\mathrm{a}$ & 4.570 & $1.503,20$ & $\mathrm{~b}$ \\
\hline
\end{tabular}

As médias seguidas pela mesma letra não diferem estatisticamente entre si nas colunas.

Echinolaena inflexa apresentou-se com maior teor de voláteis e, consequentemente, menor teor de carbono fixo e, portanto, maior inflamabilidade. A diferença entre Echinolaena inflexa e Palicourea rigida não foi significativa, mas associado aos outros fatores, como menor teor de carbono fixo, reflete a alta inflamabilidade de Echinolaena inflexa. Considerando que a lignificação é maior nos tecidos caulinares, Lavoisiera bergii foi moída incluindo os caules, o que aumentou a porcentagem de lignina nas amostras, aumentando assim o teor de carbono fixo que a coloca entre Vochysia thyrsoidea e Palicourea rigida (RAVEN; EVERT; EICHHORN, 2001). Por todo mesófilo da folha encontram-se feixes vasculares, que podem ser lignificados em maior ou menor grau dependendo da espécie. Os teores de materiais voláteis e carbono fixo são diretamente afetados pela constituição dos tecidos foliares. O maior teor de cinzas foi apresentado por Echinolaena inflexa, significativamente diferente das demais ao nível de $1 \%$ de probabilidade. Essa característica é comum em gramíneas, pois acumulam silicatos para resistência à toxidez, a ataques de insetos, para manterem-se eretas e diminuir a evapotranspiração (SÁVIO et al., 2011).

Long et al. (2006) associaram o teor de voláteis em combustíveis finos ( $<6 \mathrm{~mm}$ de espessura) com a consumabilidade, ou seja, quanto maior esse teor, maior e mais rápido é o consumo, favorecendo a propagação depois da desidratação. White e Zipperer (2010) afirmaram que o alto teor de cinzas favorece a resistência 
da planta contra o fogo, pois quanto maior esse teor, menor o teor de voláteis e carbono fixo que são os combustíveis. Dimitrakopoulos, Mitsopoulos e Kaliva (2013) encontraram teores de cinzas variando de 2 a $6 \%$ em folhas de coníferas, com menor inflamabilidade para Picea excelsa com 4,5\%, alertando para o fato de que a inflamabilidade é influenciada pelas características da comunidade vegetal e não apenas pela espécie.

Analisando as diferenças dos dados de PCS e PCU, vê-se que Lavoisiera bergii obteve o menor valor. Essa é mais uma prova de sua baixa inflamabilidade, pois gera menos calor para propagação do fogo, mesmo incluindo seu caule na amostra. As espécies estudadas classificadas como de baixa inflamabilidade praticamente emitem menos da metade do calor liberado pela gramínea num incêndio florestal, como se pode notar na Tabela 2. O PCS não reflete diretamente a inflamabilidade. De fato, combustões incompletas diminuem a combustibilidade. O maior PCS pode estar relacionado com o maior teor de lignina, mas outras variáveis interferem na inflamabilidade das folhas (RODRÍGUEZ, 2010). A relação entre PCS e inflamabilidade pode estar relacionada a mecanismos de defesa contra mortalidade causada por incêndios, como ocorre com Ulex europaeus, que, com o maior PCS $(5003,82 \mathrm{cal} / \mathrm{g})$, apresentou a menor inflamabilidade. Em contraste, Castanea sativa, com a maior inflamabilidade, mostrou o menor PCS (4091,43 cal/g). Mas isso não se aplica a Pinus pinaster, que tem PCS alto (maior que $5972 \mathrm{cal} / \mathrm{g}$ ) e também alta inflamabilidade que pode ser atribuída aos óleos essenciais e resinas foliares (NÚÑEZREGUEIRA; AÑON; CASTIÑEIRAS, 1996).

\section{Inflamabilidade das espécies classificadas}

Inter-relacionando as propriedades físicas estudadas, a Tabela 3 apresenta o ranqueamento das espécies quanto à inflamabilidade, a partir dos parâmetros mais representativos encontrados no estudo.

Tabela 3 - Principais características de inflamabilidade. Análise das relações entre as variáveis frente à inflamabilidade. Pontuação de inflamabilidade - quanto menor, menor inflamabilidade.

Table 3 - Main flammability characteristics. Analysis of the relationship between the variables front flammability. Score flammability- smaller, lower flammability.

\begin{tabular}{lccccccccccc}
\hline \multicolumn{1}{c}{ Espécies } & \multicolumn{2}{c}{$\mathbf{U}(\mathbf{\%})$} & \multicolumn{2}{c}{ MV (\%) } & \multicolumn{2}{c}{ E (mm) } & \multicolumn{2}{c}{ PCS (cal/g) } & \multicolumn{2}{c}{ PCU (cal/g) } & $\sum$ Pontos \\
\hline Vochysia thyrsoidea & 146 & $(12)$ & 73,6 & $(3)$ & 4,8 & $(4)$ & 4570 & $(3)$ & 1.503 & $(15)$ & $(37)$ \\
Palicourea rigida & 173 & $(8)$ & 76,1 & $(9)$ & 5,6 & $(2)$ & 4581 & $(4)$ & 1.297 & $(10)$ & $(33)$ \\
Lavoseiera bergii & 257 & $(4)$ & 73,9 & $(6)$ & 2,7 & $(6)$ & 4492 & $(1)$ & 816 & $(5)$ & $(22)$ \\
Echinolaena inflexa & 50 & $(16)$ & 76,8 & $(12)$ & 1,8 & $(8)$ & 4548 & $(2)$ & 2.869 & $(20)$ & $(58)$ \\
\hline
\end{tabular}

Em que: $\mathrm{U}=$ umidade; $\mathrm{MV}=$ material volátil; $\mathrm{E}=$ espessura; $\mathrm{PCS}=$ poder calorífico superior; PCU = poder calorífico na umidade de campo. Os valores entre parênteses representam a pontuação para as espécies (de 1 a 4) multiplicada pelo peso atribuído a cada parâmetro (de 1 a 5).

Os valores do somatório de pontos separam a espécie de alta inflamabilidade Echinolaena inflexa das demais. Lavoisiera bergii, apresentando a menor pontuação, é a menos inflamável, seguida por Palicourea rigida e Vochysia thyrsoidea. O somatório de pontos separou as espécies de baixa inflamabilidade em 57\% [(58-37)/37] da espécie de alta inflamabilidade.

\section{Conclusões}

Em comparação com a vegetação adjacente queimada, as espécies Vochysia thyrsoidea, Palicourea rigida, e Lavoisiera bergii apresentaram-se como espécies de baixa inflamabilidade. O elevado teor de umidade, o baixo teor de material volátil e os menores calores de combustão na umidade de campo forneceram um indicativo confirmador da baixa inflamabilidade de Vochysia thyrsoidea, Palicourea rigida e Lavoisiera bergii em comparação a Echinolaena inflexa. Portanto, considerando o levantamento de campo e as análises laboratoriais, as espécies Vochysia thyrsoidea, Palicourea rigida e Lavoisiera bergii apresentam potencial para a formação de aceiros verdes. 


\section{Agradecimentos}

Ao Programa de Pós-graduação do Departamento de Engenharia Florestal. Ao Corpo de Bombeiros Militar do Distrito Federal. À Fazenda Água Limpa da Universidade de Brasília. Ao Setor de Energia de Biomassa do Laboratório de Produtos Florestais do Serviço Florestal Brasileiro.

\section{Referências}

ALMEIDA, S. P. et al. Cerrado: espécies vegetais úteis. Planaltina: EMBRAPA Cerrados, 1998. 464 p.

ANDERSON, H. E. Forest fuel ignitibility. Fire technology, Gaithersburg, v. 6, n. 4, p. 312-319, 1970.

ASSOCIAÇÃO BRASILEIRA DE NORMAS TÉCNICAS. NBR 7190: Projeto de estruturas de madeira. Anexo B - Determinação das propriedades das madeiras para projetos de estruturas. Rio de Janeiro, 1997. $107 \mathrm{p}$.

ASSOCIAÇÃO BRASILEIRA DE NORMAS TÉCNICAS. NBR 8112: Análise química imediata do carvão vegetal. Rio de Janeiro, 1986. 5 p.

ASSOCIAÇÃO BRASILEIRA DE NORMAS TÉCNICAS. NBR 8633: Carvão vegetal - Determinação do poder calorífico. Rio de Janeiro, 1984. 13 p.

BATISTA, A. C.; BIONDI, D. Avaliação da inflamabilidade de Ligustrum lucidum Aiton (Oleaceae) para uso potencial em cortinas de segurança na região sul do Brasil. Revista Brasileira de Ciências Agrárias, Recife, v. 4, n. 4, p. 435-439, 2009.

BATISTA, A. C. et al. Evaluation of the flammability of trees and shrubs used in the implementation of green barriers in southern Brazil. General Technical Report PSW-GTR-245. In: INTERNATIONAL SYMPOSIUM ON FIRE ECONOMICS, PLANNING, AND POLICY: CLIMATE CHANGE AND WILDFIRES, 4., Mexico City, 2012. Proceedings... Mexico City: [s. n.], 2012.

CIANCIULLI, P. L. Incêndios florestais. Prevenção e combate. São Paulo: Livraria Nobel, 1981. 169 p.

DIMITRAKOPOULOS, A. P.; MITSOPOULOS, I. D.; KALIVA, A. Short communication. Comparing flammability traits among fire-stricken (low elevation) and non fire stricken (high elevation) conifer forest species of Europe: a test of the mutch hypothesis. Forest Systems, Madrid, v. 22, n. 1, p. 134-137, 2013.

GANTEAUME, A. et al. Evaluation of the flammability of trees and shrubs used in the implementation of green barriers in southern Brazil: laboratory assessment at particle level. Environmental management, New York, v. 52, n. 2, p. 467-480, 2013.

HARIDASAN, M. Alumínio é um elemento tóxico para as plantas nativas do cerrado. Fisiologia vegetal: práticas em relações hídricas, fotossíntese e nutrição mineral. Barueri: Manole, 2006. 466 p.

HEIKKILÄ, T. V.; GRÖNOVIST, R.; JURVÉLIUS, M. Handbook on forest fire control: a guide for trainers. Finland: National Board of Education, 1993. 239 p. (Forestry Training Programme, v. 21).

HULL, B. et al. Forest management in the interface: reducing fire risck. Document FOR 179, Forest Management in the Interface series of the School of Forest Resources and Conservation. Florida: School of Forest Resources and Conservation, 2012. 5 p.

LONG, A. J. et al. Quantifying and ranking the flammability of ornamental shrubs in the southern United States. In: FIRE ECOLOGY AND MANAGEMENT CONGRESS, 2006. Proceedings... [s. 1.: s. n.], 2006. p. 13-17.

MARTIN, R. E. et al. Assessing the flammability of domestic and wildland vegetation. In: CONFERENCE ON FIRE AND FOREST METEOROLOGY, 12., 1993, Georgia. Proceedings... Georgia: [s. n.], 1993. p. 26-28. 
MUNHOZ, C. B. R.; EUGÊNIO, C. U. O.; OLIVEIRA, R. C. Vereda: guia de campo. Brasília: Rede de Sementes do Cerrado, 2011. 224 p.

MURRAY, B. R.; HARDSTAFF, L. K.; PHILLIPS, M. L. Differences in leaf flammability, leaf traits and flammability-trait relationships between native and exotic plant species of dry sclerophyll forest. PloS one, Konstanz, v. 8, n. 11, e79205, 2013.

NÚÑEZ-REGUEIRA, L.; AÑON, J. A. R.; CASTIÑEIRAS, J. P. Calorific values and flammability of forest species in Galicia. Coastal and hillside zones. Bioresource technology, Great Britain. v. 57, n. 3, p. 283-289, 1996.

ONIGEMO, A. E. Avaliação de índices de risco de incêndio em áreas com predominância de gramíneas cespitosas na sub-região da Nhecolândia, Pantanal-MS. 2007. 142 f. Tese (Doutorado em Ecologia) Universidade Federal de Mato Grosso do Sul, Campo Grande, 2007.

PIRANI, F. R.; SANCHEZ, M.; PEDRONI, F. Fenologia de uma comunidade arbórea em cerrado sentido restrito, Barra do Garças, MT, Brasil. Acta Botanica Brasilica, Belo Horizonte, v. 23, n. 4, p. 1096-1109, 2009.

RAVEN, P. H.; EVERT, R. F.; EICHHORN, S. E. Regulando o crescimento e o desenvolvimento: os hormônios vegetais. In: RAVEN, P. H. Biologia vegetal. [s. 1.: s. n.], 2001. v. 6. p. 649-675.

RODRÍGUEZ, M. P. R. Manejo del fuego. La Habana: Editorial Felix Varela, 2010. 254 p.

SÁVIO, F. L. et al. Produção de biomassa e conteúdo de silício em gramíneas forrageiras sob diferentes fontes de silicato. Semina: Ciências Agrárias, Londrina v. 32, n. 1, p. 103-110, 2011.

SILVA, D. A.; KLINK, C. A. Dinâmica de foliação e perfilhamento de duas gramíneas C4 e uma C3 nativas do Cerrado. Revista Brasileira de Botânica, São Paulo, v. 24, n. 4, p. 441-446, 2001.

SILVA, F. A. S.; AZEVEDO, C. A. V. Principal components analysis in the software assistat-statistical attendance. In: WORLD CONGRESS ON COMPUTERS IN AGRICULTURE, 2009, Nevada. Proceedings... Nevada: [s. n.], 2009. p. 22-24.

SILVA JÚNIOR, M. C.; SANTOS, G. C. 100 Árvores do Cerrado: guia de campo. [s. 1.]: Rede de sementes do Cerrado, 2005. 278 p.

SOARES, R. V.; BATISTA, A. C. Incêndios florestais: controle, efeitos e uso do fogo. Curitiba: UFP, 2007. 264 p.

TIAN, X.; SHU, L.; WANG, M. Study on eight tree species' combustibility and fuelbreak effectiveness. In: INTERNATIONAL WILDLAND FIRE CONFERENCE, 2007, Sevilha. Proceedings... Sevilha: [s. n.], 2007. p. 1-11.

VITAL, B. R. Métodos de determinação da densidade da madeira. Viçosa, MG: SIF, 1984. (Boletim Técnico, 1).

WEISE, D. R. et al. Use of the cone calorimeter to detect seasonal differences in selected combustion characteristics of ornamental vegetation. International Journal of Wildland Fire, Rosyn, v. 14, n. 3, p. 321-338, 2005.

WHITE, R. H.; ZIPPERER, W. C. Testing and classification of individual plants for fire behaviour: plant selection for the wildland-urban interface. International Journal of Wildland Fire, Rosyn, v. 19, n. 2, p. 213-227, 2010.

YONG-HUAN, C. Fire management in China: application and developmen to fuelbreaks. In: WILDFIRE 2007, SESSION REGIONAL SESSION D, 2007, Sevilha. Proceedings... Sevilha: [s. n.], 2007.

ZHANG, Z.; ZHANG, H.; ZHOU, D. Flammability characterisation of grassland species of Songhua Jiang-Nen Jiang Plain (China) using thermal analysis. Fire Safety Journal, Oxford, v. 46, n. 5 , p. $283-288,2011$. 